\title{
Kolorektal Kanser Nedeniyle Ameliyat Edilen Hastaların Değerlendirilmesi
}

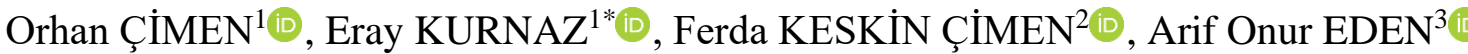

1. Erzincan Binali Yıldırım Üniversitesi Tıp Fakültesi Genel Cerrahi Anabilim Dalı

2. Erzincan Binali Yıldırım Üniversitesi Tıp Fakültesi Patoloji Anabilim Dalı

3. Erzincan Binali Yıldırım Üniversitesi Tıp Fakültesi Acil Tıp Anabilim Dalı

Geliş / Received: 27.11.2019, Kabul / Accepted: 16.12.2019

Öz

Kolorektal kanserler gastrointestinal sistemde en sık görülen malign lezyonlardır. Kanserden ölümlerin en sık üçüncü sebebi durumundadır. Erken evrelerde tanı almaları durumunda mortalite ve morbiditesi daha düşüktür, cerrahi olarak kür sağlanma şansı daha fazla olmaktadır. Erzincan Binali Yıldırım Üniversitesi Mengücek Gazi Eğitim Araştırma Hastanesi'nde 2013-2018 yılları arasında kolorektal kanser nedeniyle ameliyat edilen 86 hasta çalışmaya dahil edildi. Hastaların en sık başvuru semptomları rektal kanama, anemi, kilo kaybı, karın ağrısı ve dışkılama alışkanlığında değişikliklerdi. Kolorektal kanserlerde en önemli prognostik faktör tanı anındaki tümör evresidir. Geç teşhis morbidite ve mortalitede artışa neden olmaktadır. Ortaya çıkan semptomların hasta tarafından önemsenmesi, hekim tarafından gerekli tetkiklerin vaktinde yapılması ve bu konuda toplumsal bilincin arttırılması sayesinde tümörün erken tanısının sağlanabileceği kanaatindeyiz.

Anahtar Kelimeler: kolorektal kanser, erken tan1, tarama program1, postoperatif takip

\section{Evaluation of Patients Operated for Colorectal Cancer}

\begin{abstract}
Colorectal cancers are the most common malignant lesions in the gastrointestinal tract. It is the third most common cause of cancer deaths. Mortality and morbidity are lower if diagnosed at an early stage. 86 patients who were operated for colorectal cancer in Erzincan Binali Y1ldırım University Mengücek Gazi Training and Research Hospital between 2013-2018 were included in the study. The most common presenting symptoms were rectal bleeding, anemia, weight loss, abdominal pain and changes in the habit of defecation. The most important prognostic factor in colorectal cancer is the tumor stage at the time of diagnosis. Late diagnosis leads to increased morbidity and mortality. We believe that the early diagnosis of the tumor can be provided by the importance of the patient's symptoms, the necessary examinations performed by the physician on time, and the increase of social awareness in this regard.
\end{abstract}

Keywords: colorectal cancer, early diagnosis, scanning program, postoperative follow-up 


\section{Giriş}

Kolorektal kanserler gastrointestinal sistemde en s1k görülen malign lezyonlardır. Kanserden ölümlerin en sık üçüncü sebebi durumundadır. İnsidansı kadınlarda ve erkeklerde benzerdir. Ulusal tarama programlarının uygulanması özellikle elli yaşın altındaki bireylerde insidansın azalmasını sağlamıştır. Ancak elli yaşından gençlerde insidans artmakta ve hastalık daha mortal seyretmektedir (Siegel vd., 2017). Kolorektal kanserler yavaş büyüyen lezyonlar olup tanı anında genellikle ileri evrelerde olmaktadır. Erken evrelerde tanı almaları durumunda mortalite ve morbiditesi daha düşüktür, cerrahi olarak kür sağlanma şansı daha fazla olmaktadır (Hawk vd., 2002). Bu çalışmamızda, kliniğimizde kolorektal kanser nedeniyle ameliyat edilen olguları sunmak ve literatür eşliğinde değerlendirme yapmayı amaçladık.

\section{Materyal ve Metot}

Erzincan Binali Yıldırım Üniversitesi Mengücek Gazi Eğitim Araştırma Hastanesi'nde 2013-2018 y1lları arasında kolorektal kanser nedeniyle ameliyat edilen 86 hasta çalışmaya dahil edildi. Hasta bilgilerine hastane otomasyon sisteminden ulaşıldı. Hastaların yaşı, cinsiyeti, acil veya elektif vaka oluşu, tümör lokalizasyonu, yapılan ameliyat çeşidi, histopatolojik sonuç ve çıkarılan lenf nodu sayıları ile postoperatif karşılaşılan komplikasyonlar excel dosyasına kayıt edildi.

\section{Bulgular}

Çalışmaya dahil edilen 86 hastanın 46's1 (\%53.4) kadın, 40’1 (\%46.6) erkekti. 67 hasta elektif şartlarda ameliyat edildi (\%77.9). Hastaların \%22.1'i ise akut batın veya obstrüksiyon kliniği nedeniyle acil olarak ameliyata alındı. Hastaların en sık başvuru semptomları rektal kanama, anemi, kilo kaybı, karın ağrısı ve dışkılama alışkanlığında değişikliklerdi. En genç hastamız 22 yaşında bir kadın hasta iken en yaşlı hastamız 94 yaşında erkek hasta idi.

Tümör lokalizasyonuna göre değerlendirdiğimizde ise; 26 hastada sigmoid kolon tümörü (\%30,2), 21 hastada rektum tümörü $(\% 24,6), 19$ hastada inen kolon tümörü $(\% 22,1), 9$ hastada çıkan kolon tümörü $(\% 10,4), 6$ hastada çekum tümörü $(\% 6,9), 5$ hastada transvers kolon tümörü $(\% 5,8)$ tespit edildi. Uygulanan ameliyat yöntemlerine göre değerlendirdiğimizde; 43 hastaya sol hemikolektomi (\%50), 17 hastaya sağ hemikolektomi $(\% 19,7), 16$ hastaya low anterior rezeksiyon $(\% 18,6)$ yapıldı. $\mathrm{Bu}$ işlemlerden 20'si (\%23.2) laparoskopik olarak gerçekleştirildi. Acil şartlarda başvuran 10 hastada (\%11.6) ise Hartmann prosedürü uyguland1.

Postoperatif en s1k görülen komplikasyon yüzeyel cerrahi alan enfeksiyonları idi. 10 hastada $(\% 11,6)$ bu durumla karşılaşıldı. Low anterior rezeksiyon yapilan 1 hastada (\%6.25) ve sol hemikolektomi yapilan 1 hastada (\%2.3) anastomoz kaçağı gelişmesi üzerine hastalar tekrar ameliyata alındı. $\mathrm{Bu}$ hastalarda anastomoz bozulup Hartmann prosedürü uygulandi. Postoperatif ileus gelişen 3 hastanın (\%3.4) konservatif takip sonrası kliniği düzeldi. Bütün hastalara postoperatif düşük molekül ağırlıklı heparin ile profilaksi yapıldı. 1 hastamızda (\%1.2) pulmoner emboli gelişti ve bu hastaya tanı sonrasında tedavi dozunda düşük molekül 
ağırlıklı heparin uygulandı. Acil operasyona alınıp tümör perforasyonu ve sepsis kliniği mevcut 2 hasta (\%2.3) postoperatif erken dönemde exitus oldu.

Hastaların 19'unda (\%22.1) bir veya daha fazla metastatik lenf nodu tespit edildi. Postoperatif histopatolojik inceleme sonras1; 75 hastada (\%87.2) adenokarsinom, 5 hastada (\%5.8) müsinöz karsinom, 4 hastada (\%4.6) taşlı yüzük hücreli karsinom, 1 hastada (\%1.2) yüksek dereceli displazi ve 1 hastada (\%1.2) ise endometrium kanseri metastazı olduğu görüldü.

\section{Sonuç ve Tartışma}

Kolorektal kanserler, kanserle ilgili mortalite ve morbiditenin en önemli sebeplerindendir. Kolorektal kanser sıklığ 1 farklı toplumlarda farklı oranlarda bildirilmekle birlikte ABD'de kadın ve erkeklerde hem görülme sıklığı hem de mortalite oranı açısından \%9 oranıyla üçüncü sirada gelmektedir (Siegel vd., 2013). Ülkemizde yapılan bir çalışmada kolorektal kanserlerin erkeklerde \%25.8 ile birinci sırada, kadınlarda ise \%17.7 ile ikinci sırada olduğu rapor edilmiştir (Gürsu vd., 2012).

Kolorektal kanserler lokalizasyonlarına göre değerlendirildiğinde en sik olarak rektum ve rektosigmoid bölgede görülmektedir (Golematis vd., 1989). Çalışmamızda, literatür ile uyumlu olarak, \% 54.8 ile en s1k rektum ve rektosigmoid bölgede tümör saptanmıştır.

Kolorektal kanser hastalarında en sik görülen semptom sağ kolon için kilo kaybı ve anemi, sol kolon için ise rektal kanama ve anemidir (Majumdar vd., 1999). Çalışmamızda da rektal kanama ve anemi literatürle uyumlu olarak en sık ortaya çıkan semptomlardi.

Kolorektal kanserlerin tanisinda, evrelendirilmesinde ve metastazların araştırılmasında radyolojik görüntüleme yöntemleri önemli bir yer tutmaktadır. Bu tetkiklerden en önemlileri bilgisayarlı tomografi (BT), manyetik rezonans görüntüleme (MRG), endorektal ultrasonografi (USG) ve pozitron emisyon tomografi (PET)'dir. MRG rektum tümörlerini kolonun diğer bölgelerine yerleşmiş tümörlere göre daha iyi tanıyabilmekte ve evrelemektedir. Özellikle mezorektal fasyanın değerlendirilmesinde ve hastanın lokorejyonel evrelendirilmesinde MRG kullanılmaktadır (Wald vd., 2006). Çalışmamıza dahil edilen hastaların değerlendirilmesinde ve evrelendirilmesinde toraks, tüm batın tomografi ve rektum kanserli olgularımızda pelvik MRG kullanıldı. Rektum kanserli olgularımızın 7'si lokal ileri evre kabul edilerek öncelikle neoadjuvan tedaviye yönlendirildi. Neoadjuvan tedavi sonrası bu hastalar ameliyat edildi.

Kolorektal kanser cerrahisi sonras1 komplikasyon oranları \%41.6 olarak bildirilmektedir (Killingback vd., 1998). Ameliyat sonrası erken dönemde anastomoz kaçağı, apse veya fistül gelişimi, barsak tıkanması, yara yeri problemleri gibi komplikasyonlar gelişebilmektedir. Anastomoz kaçağı en ciddi komplikasyonlardan biridir ve yaklaşık olarak \%5 oranında görülür. Özellikle alt rektum kanseri hastalarında daha sik görülmektedir (Vignali vd., 1997). 
Malignite durumu ve majör cerrahi girişim nedeniyle kolorektal kanserli hastalarda tromboembolik olaylara sik rastlanılmaktadır. Literatürde kolorektal kanserli hastalarda profilaksi uygulanmaz ise pulmoner emboli için \%3 risk oranı bildirilmektedir (Stahl vd., 2006). Çalışmamızda 1 hastada (\%1.2) pulmoner emboli görüldü.

Kolorektal kanser cerrahisi sonrası cerrahi alan enfeksiyonları için \% $10-30$ gibi oldukça farklı oranlar bildirilmektedir (Dorudi vd., 2002). Çalışmamızda cerrahi alan enfeksiyonu oranı \%11.6 olarak ölçüldü. Kolorektal kanser cerrahisi sonrası erken dönem ileus oranı \%2-10 arasında bildirilmektedir (Alvarez vd., 2011). Çalışmamızda ise bu oran \%3.4 olarak tespit edildi. $\mathrm{Bu}$ hastalar konservatif takip sonrası klinik düzelme gösterdi.

Kolorektal kanserlerde klinik semptomların ilk ortaya çıkışı ile tanı konulması arasında geçen sürenin uzun olması prognozu olumsuz yönde etkilemektedir. Bu durum hastaların ileri evrelerde tanı almasina neden olmaktadır. Özellikle yaşlı hastalarda bu sürenin uzun olması acil ameliyat gerektirmekte ve buna bağlı olarak da morbidite ve mortalite artmaktadır (Aydın vd., 2015).

Genel itibariyle kolorektal kanserlerde en önemli prognostik faktör tanı anındaki tümör evresidir. Geç teşhis morbidite ve mortalitede artışa neden olmaktadır. Ortaya çıkan semptomların hasta tarafindan önemsenmesi, hekim tarafından gerekli tetkiklerin vaktinde yapılması ve bu konuda toplumsal bilincin arttırılması sayesinde tümörün erken tanısının sağlanabileceği kanaatindeyiz.

\section{Kaynaklar}

Alvarez-Downing, M., Klaassen, Z., Orringer, R., Gilder, M., Tarantino, D., Chamberlain, R.S. 2011. "Incidence of small bowel obstruction after laparoscopic and open colon resection" Am J Surg, 201(3):411-5.

Aydın, İ., Şehitoğlu, İ., Özer, E., Pergel, A., Bedir, R., Güçer, H., Şahin, D.A. 2015. ' Kolorektal Kanser Nedeniyle Opere Ettiğimiz Hastaların Değerlendirilmesi', Kocatepe Tip Dergisi, 16:102-109.

Dorudi, S., Steele, R.J., Mc Ardle, C.S. 2002. "Surgery for colorectal cancer'" British Medical Bulletin, 64:101-18.

Golematis, B.C., Tzardis, P.J., Al Ahwal, J., Charitopoulos, N., Peveretos, P. 1989. "Site distribution of carsinoma of the large intestine: a retrospective study of 600 cases" Dis Colon Rectum, 32(1):14-6.

Gürsu, R.U., Kesmezacar, Ö., Karaçetin, D., Mermut, Ö. B., Güner, Ş.İ. 2012. "İstanbul Eğitim ve Araştırma Hastanesi Onkoloji Birimi: yeni kurulan bir ünitenin 18 aylık sonuçları.' Istanbul Med J, 13(1):13-8.

Hawk, E.T., Limburg, P.J., Viner,. J.L. 2002. 'Epidemiology and prevention of colorectal cancer' Surg Clin N Am, 82:90541

.Itatsu, K., Sugawara, G., Kaneoka, Y. 2013. "'Risk factors for incisional surgical site infections in elective surgery for colorectal cancer: focus on intraoperative meticulous wound management' Surg Today, DOI 10-1007/s00595-013-0677-3.

Killingback, M., Barron, P., Dent, O. 2002. 'Elective resection and anastomosis for colorectal cancer: a prospective audit of mortality and morbidity 1976- 1998' ANZ J Surg, 72(10):689-98.

Majumdar, R.S., Fletcher, R.H., Evans, A.T. 1999. "How does colorectal cancer present? symptoms, duration, and clues to 
location" Am J Gastroenterol, prevention of venous thrombosis" Dis 94(10):3039-45.

Colon Rectum, 49(10):1477-83.

Siegel, R, Naishadham, D., Jemal, A. 2012

Vignali, A., Fazio, V.W., Lavery, I.C. 1997.

"Cancer Statistics 2012" CA Cancer J "'Factors associated with the occurrence of Clin, 62(1):10-29.

Siegel, RL., Miller, K.D., Fedewa, S.A. 2017. "Colorectal cancer statistics', $C A$ Cancer J Clin , 67(3):177-193. leaks in stapled rectal anastomoses: a review of 1014 patients' J AM Coll Surg, 185(2):105-13.

Wald, C., Scheirey, C.D., Tran, T.M.,

Stahl, T.J., Gregorcyk, S.G., Hyman, N.H., Erbay, N. 2006. ' An update on imaging of Buie, W.D. 'Practice parameters forthe colorectal cancer', Surg Clin N Am, 86(4):819-47. 